\title{
Premenstrual Tension Syndrome and its Impact on Family Function
}

\author{
Tayseer M. Metwally ${ }^{1}$ and Ahmed G. Abdelrahman² \\ ${ }^{1}$ Department of Family Medicine, Faculty of Medicine, Suez University, Suez, Egypt \\ ${ }^{2}$ Department of Family medicine, Faculty of Medicine, Suez Canal University, Ismailia, Egypt
}

\begin{abstract}
:
Background: Premenstrual tension syndrome (PMTS) is defined as periodic physical, cognitive, behavioral and mood changes during the premenstrual phase, about $90 \%$ of women report some PMS symptoms which adversely affect their normal performance. Objectives: To estimate the prevalence and risk factors of PMTS among undergraduate female students at Suez University, and its effect on family function. Methods: An analytic cross-sectional study was conducted using an online questionnaire. Two validated tools were used for assessment; the PMTS-OR scale for premenstrual tension syndrome assessment and family APGAR score for family function assessment, 190 participants among female students at Suez University shared in the study during the period between February to April 2020. Results: The mean age of participants was 19.95 years, $60.5 \%$ of them were students in theoretical colleges, 3.7\% had no PMTS while 14.7\%, 42.1\%, 39.5\% had mild, moderate, and severe premenstrual tension syndrome, respectively. Drinking coffee, late sleep, regularity of menstruation and educational attainment were significantly associated with PMTS. $15.8 \%$ were severely dysfunctional, $45.3 \%$ of participant had moderate family dysfunction, and $38.9 \%$ were highly functional. There was a statistically significant relationship between family dysfunction and both regularity of menstruation and premenstrual tension syndrome. Moderate and severe forms of PMTS were associated with increased probability of having family dysfunction. Conclusions: This study proved that PMTS is highly prevalent among undergraduate female students at Suez University and has a significant association with family dysfunction, so health awareness programs to girls and their families are needed to improve knowledge regarding menstrual disorders.
\end{abstract}

Key words: APGAR Score, Family Function Assessment, Menstrual Disorders, Premenstrual Syndrome, Premenstrual Tension Syndrome

\section{Introduction:}

International Society of Premenstrual Disorders (ISMDs) divides PMS into 'core' and 'variant' using precise criteria. Core (or typical) premenstrual disorders (PMDs) are the most common type, the symptoms are nonspecific (predominantly physical, emotional or mixed) and recur with spontaneous ovulatory cycles, and impair daily functioning, affect the work or school performance, or interpersonal relationships ${ }^{(1)}$, premenstrual disorders include premenstrual dysphoric disorder, Premenstrual syndrome, and premenstrual deteriorating of another medical condition. Severity of symptoms varies from standardizing, mild to severe and disabling symptoms. ${ }^{(2)}$

To diagnose premenstrual tension syndrome, family physicians must confirm a pattern of symptoms. The length of symptom manifestation ranges from few days to two weeks. Frequently worsen six days before menses, and peak at the previous two days, there must be a symptom-free period before ovulation. Usually, women have the same setting of symptoms from one cycle to the next. ${ }^{(3)}$ The PMS is highly common affecting $(86.3 \%)$ of school girls in Beni-Sweif, Egypt, 
risk factors for it were age, education, marital status, and sleeping hours. ${ }^{(4)}$

According to the fifth edition of diagnostic and statistical manual of mental disorder the main feature of premenstrual dysphoric disorder is seen in most of the menstrual cycles with 5 or more symptoms during the last week of luteal phase which include:1- Apparent depression, sense of desperation 2- Prominent anxiety, tension, sense of excitation and restlessness 3Obvious emotional instability 4- Apparent and stable anger or excitability 5- Diminished interest in routine activities 6- Apparent difficulty in concentrating 7- Sleepiness and rapid fatigue 8- Apparent change in appetite, eating too much 9- Sleeping disturbances (sleeping too much or too little) 10- Sense of languor and losing control 11- Other physical symptoms like and breast tenderness and pain, headache, pain in joints, muscles and weight gain which apparently interfere the work, education, social activities and social relations. ${ }^{(5)}$ The quality of interactional relationships between and among family members is a factor in the patient's health status and there is close correlation between medical problems and family member conflicts.

Family dysfunction can be assessed with the Family APGAR which is a screening questionnaire that measures the patient's perception of five components of family function. Studies suggest that most family dysfunction problems are hidden under a pretense of physical symptoms. ${ }^{(6)}$ There are no previous studies assessed the relation between PMTS and family function, this study was carried out to estimate the prevalence and risk factors of PMTS, and its impact on family function among undergraduate female students in Suez University.

\section{Methods:}

Suez University is an Egyptian governmental institution including 12 faculty, number of undergraduate female students in the academic year 2019/2020 was about 8021 female students. Participants in this study were recruited from the undergraduate female students by using an online anonymous selfadministered questionnaire created through Google Forms.

The calculated sample size is 180. This number is large enough to detect a $12 \%(+/-5 \%)$ prevalence of premenstrual tension syndrome, at a $95 \%$ level of confidence, an $80 \%$ power of study, and a $10 \%$ dropout rate. Sample size equation: $n=(Z 1-a / 2 / d) 2 * p^{*}(1-p)$ Where $n=$ Calculated sample size. $\mathrm{Z}$ a/2 = the critical value that divides the central $95 \%$ of the $\mathrm{Z}$ distribution from the $5 \%$ in the tail $(=1.96) \cdot \mathrm{p}=$ the estimated prevalence of premenstrual tension syndrome $(12 \%) \mathrm{d}=$ Margin of error (5\%).190 participants shared in the study in the period from February to April 2020, answering the questions considered as consent from the participants to share in the study and their questionnaires were anonymous and kept confidential.

The questionnaire consisted of three parts, the first part was for the socio-demographic 
data, medical and menstrual history (age, if attached to theoretical or practical college and in which years of study, weight, height, number of brothers and sisters, educational level of the mother and father, marital status, any special habits as drinking coffee, tea, soda or sleeping late, if suffering from any disease require continuous treatment, if exposed to surgeries, age of menarche, regularity of menstrual cycle, number of bleeding days monthly, amount of daily bleeding, symptoms associated with menses, if the symptoms affect the attendance in the colleges or affect educational attainment), BMI was calculated by dividing the weight (in kilograms) by height (in meters squared) and cutoff point of overweight equal or more than 25 $\mathrm{kg} / \mathrm{m}^{2}$.

Part two comprised the tool for assessment of premenstrual tension syndrome; we used the modified (PMTS-OR) scale, which is simple, reliable, sensitive, and valid. Students were asked if they experienced from symptoms in the week prior to menses in the previous 3 months. The tool consists of 11 domains with the total maximum score 40. Answers according to the severity take a score with a range of 0 to 4 in nine domains and 0 to 2 in two domains, total score between 10 and 17 has been proposed as mild symptoms, between 18 and 27 as moderate symptoms, and more than 27 as severe symptoms. ${ }^{(7)}$

Part three included the assessment of family function using APGAR score questionnaire of Smilkstein (1978). These questions allow for the assessment of the individual's satisfaction with their family functioning, based on elements considered essential in the family unit, according to the acronym APGAR which had been applied to the functional components of Adaptability, Partnership, Growth, Affection, and Resolve.

The APGAR questionnaire consists of five questions regarding the components of family function, the student checks one of three choices that are scored as "almost always (2 points), some of the time (1 point), or hardly ever ( 0 points)." The sum of scores can be zero to ten points and families can be characterized as: a functional family (8-10) or dysfunctional family. A dysfunctional family can still be classified as mild (4-7) and severely dysfunctional (0-3)

Data management and analysis: The information has been revised, coded, and analysed using SPSS package version number 26. Quantitative data were referred to as mean and standard deviation (SD). Qualitative data were stated as frequencies (n) and percentages $(\%)$. Chi-square and Fisher's exact tests were used to determine the association between qualitative variables. Binary logistic regression had been used to recognize predictive factors of family dysfunction, and $\mathrm{p}$-value $\leq 0.05$ was considered significant.

\section{Results:}

Socio-demographic characteristics: One hundred and ninety female university students shared in this study with a mean age of 19.95 
years, $60.5 \%$ were students in theoretical based faculties, and about half of students (48.9\%) registered as middle years' students. Most participants had brother(s) $(85.3 \%)$ and /or sister(s) $(79.5 \%)$.

About fifty-two percent (52.1\%) of the study population had fathers with high education, while $51.6 \%$ of their mothers had only primary or secondary degrees. The main marital status reported was single ( $87.9 \%$ ), while only $10.5 \%$ were engaged (Table 1).

Premenstrual tension syndrome: Forty-two percent of all students $(42.1 \%)$ had moderate form of premenstrual tension syndrome, severe and mild forms were less frequent $39.5 \%$ and $14.7 \%$ respectively. Only $3.7 \%$ had no PMTS

\section{(Figure 1).}

The mean age of menarche was $13.27 \pm$ (1.45) years and it had no significant relation with PMTS, factors with significant association with PMTS were drinking coffee, late sleep, regularity of menstruation and educational attainment (Table 2).

Family APGAR score: Most of participants had no history of chronic diseases $(91.6 \%)$ or previous surgeries $(80.0 \%)$. In $67.9 \%$ of students the menstrual cycle was regular with normal duration (3 to 7 days) in $88.4 \%$ and average amount in $52.1 \%$ of them. There was a statistically significant relation between family dysfunction and both regularity of menstruation and premenstrual tension syndrome (Table 3).

Binary logistic regression analysis revealed that the only predictors of family dysfunction were having moderate and severe forms of PTMS, as they were associated with about 11 and 15 times increase in probability of having family dysfunction respectively (Table 4).

\section{Discussion:}

Socio-demographic and history: One hundred and ninety undergraduate female students in Suez University shared in this study with the age range of 17 to 26 years old and a mean age of 19.95 years, which is average of age group of female students in other studies as in the USA the mean age of the participants was 16.5 years $( \pm 1.3 \mathrm{SD}),{ }^{(8)}$ in Thailand was between the age of 16 and 20, ${ }^{(9)}$ in Bahrain was $22( \pm 4.5),{ }^{(10)}$ in Assiut University undergraduate nursing female students were between 18 and 25 years old. ${ }^{(11)}$ The main marital status reported was single in the majority $87.9 \%$ of students, $10.5 \%$ were engaged, so as a whole $(98.4 \%)$ were not married, this can be explained that in Egypt, females in high education rarely got married except after finishing learning period in their faculties which is similar to other studies where participants were single $98.9 \%,{ }^{(9)} 92 \%,{ }^{(12)} 91.2$ $\%,^{(13)}$ and $80 \% .^{(11)}$

The majority of the female students $(50.5 \%)$ had a normal body mass index, this is had no association with PMTS, which is different from results of another study which stated a significant relation between BMI and the occurrence of PMS as obese women had significantly higher risks, and that BMI was also positively associated with risk of specific physical and emotional symptoms. ${ }^{(14)}$ 
Considering the age of menarche, the current study demonstrated that the mean age of menarche was $13.27( \pm 1.45)$, which is almost similar to the mean age described by other studies $^{(6,9,11,13)}$, and that it does not have any association with PMTS.

Prevalence: In this study only $3.7 \%$ had no PMTS while $96.3 \%$ had symptoms with a variable severity. This finding is in agreement with that of a study which showed the prevalence is $(93 \%),{ }^{(10)}$ in Taiwan $39.85 \%,{ }^{(15)}$ in Iran $39.4 \%$, $^{(16)}$ in India $18.4 \%,{ }^{(17)}$ in other studies in Egypt prevalence of PMS was $(86.3 \%),{ }^{(4)} 80.2 \%{ }^{(18)}$ and $(89.6 \%) .^{(19)}$

About half of our participants $(48.9 \%)$ registered as middle years' students, while in another study $37.2 \%$ were first year students, $23.7 \%$ were fourth year, $22.9 \%$ were second year, $11.7 \%$ were third year, and $4.5 \%$ were graduate students. ${ }^{(9)}$

Severity: The severity of PMTS among this study was (39.5\%) severe, (42.1\%) moderate, and $14.7 \%$ mild forms of PMS, In a study in Bahrain PMS symptoms were mild in (41\%), moderate in $(52 \%)$, and severe in only $6 \%$ of the participants, ${ }^{(10)}$ in Iran $60.6 \%$ had mild, $25.1 \%$ had moderate and $14.2 \%$ had severe PMS, ${ }^{(16)}$ while in Japan, rates of moderate to severe PMS was $9.7 \%,{ }^{(22)}$ A total of $41 \%$ of the participants in a study in Thailand had mild symptoms did not interfere with daily functioning while $53 \%$ had moderate symptoms with significant discomfort; $6 \%$ of the participants had severe symptoms interfere daily function (such as interpersonal relationships and school performance), ${ }^{(9)}$ Indian study stated that moderate to severe PMS was $14.7 \%$, $^{(17)}$ in Assiut university slightly more than half of students had mild PMS followed by moderate PMS while the minority of them had severe $\mathrm{PMS}^{(11)}$ in Dakahlia a study registered mild PMS in $55.8 \%$, moderate among $34.2 \%$, strong among $9.6 \%$ and severe among $0.4 \%,{ }^{(11)}$ In an Iranian study $66.3 \%$ of those surveyed had mild PMS, $31.4 \%$ had moderate symptoms and only $2.3 \%$ of participants suffered severe symptoms, ${ }^{(13)}$ and Saudi Arabia stated that the frequency of PMS was mild in $45 \%$, moderate in $32.6 \%$, and severe in $22.4 \%$ of cases. ${ }^{(20)}$

Risk factors: Our findings showed a significant association between PMTS and coffee intake which is consistent with results of other studies as in Saudi Arabia, ${ }^{(21)}$ The observed effect of tea did not reach significant level may be due to a lower dose effect of caffeine per cup in comparison to coffee, which is similar to our results as tea and soda had no significant association with PMS which had been explained as one cup of caffeinated coffee usually has 60$85 \mathrm{mg}$ of caffeine while that for tea and cola drinks are reported to be $20-30 \mathrm{mg}$ and $18 \mathrm{mg}$ per cup, respectively, ${ }^{(18)}$ although another study suggested that coffee intake is not associated with PMS. ${ }^{(22)}$

This study proved that sleeping late was associated with increased risk of PMTS which is consistent with another study which proved that Sleep affect PMS among high school 
students, ${ }^{(23)}$ and in another study sleeping hours were determinants for PMS. ${ }^{(4)}$

The regularity of menstruation and educational attainment were statistically significant associated with PMTS, while other factors as previous surgeries, chronic illness, age of menarche, amount, or days of menstruation, proved in this study, as with no significant association with it.

Family function: Family APGAR score assessment revealed that $45.3 \%$ of participant had moderate family dysfunction, $15.8 \%$ were severely dysfunctional and $38.9 \%$ were highly functional, there was a statistically significant relation between family dysfunction and both regularity of menstruation and premenstrual syndrome.

In an Iranian study impairment on the home/family scale was rated moderate or severe by $52 \%$ of the teen respondents. Impairment in social life/activities was rated moderate or severe by $39 \%$ of the teens, and impairment in school was rated moderate or severe by $36 \%$ of the teens ${ }^{(10)}$, life quality score was low in more than half of the medical students, especially in psychological and social components, and the quality of life score means in mental health and environmental health decreases as the PMS score average increases, ${ }^{(16)}$ and In Thailand around $40 \%$ of the respondents noticed that sadness; depression, confusion, irritability, and conflicts with friends/ boyfriends were common before menstruation. Less than $30 \%$ reported a high rate of anxiety, withdrawal feeling, ineffective coping, and bloated body image. $28 \%$ of the respondents suffered these symptoms before every period. ${ }^{(9)}$

Our findings proved significant association between PMS symptoms and family dysfunction as a binary logistic regression analysis revealed that the only predictor of family dysfunction was having moderate or severe forms of PMS, as they were associated with about 11 and 15 times increase in probability of having family dysfunction, respectively.

Limitations: As this study was during the beginning of the emergence of Corona, we used an online questionnaire to collect data from the undergraduate female students in Suez University

Conclusion: This study proved that PMS is highly prevalent among undergraduate female students in Suez University, Egypt, and has a significant association with family dysfunction, Health education program is necessary to provide students and their families with required information for coping in a healthy way with premenstrual syndrome.

Abbreviations: premenstrual syndrome (PMS), premenstrual tension syndrome(PMTS), The International Society of Premenstrual Disorders(ISMDs), premenstrual disorders (PMDs)

\section{Competing interests: No}

Funding: No 
Acknowledgement: We are grateful to all Suez university students who participated in the study.

\section{References:}

1. Gnanasambanthan S, Datta S. Premenstrual syndrome. Obstetrics, Gynaecology \& Reproductive Medicine. 2019;29(10):281-5.

2. Yonkers KA, Simoni MK. Premenstrual disorders. American journal of obstetrics and gynecology. 2018;218(1):68-74.

3. Yoshimi K, Shiina M, Takeda T. Lifestyle Factors Associated with Premenstrual Syndrome: A Cross-sectional Study of Japanese High School Students. Journal of pediatric and adolescent gynecology. 2019;32(6):590-5.

4. Arafa AE, Senosy SA, Helmy HK, Mohamed AA. Prevalence and patterns of dysmenorrhea and premenstrual syndrome among Egyptian girls (12-25 years). Middle East Fertility Society Journal. 2018;23(4):486-90.

5. Khalatbari J, Salimynezhad S. The Effect of Relaxation on Premenstrual Syndrome in Dormitory Students of Azad Tonekabon University of Iran. Procedia - Social and Behavioral Sciences. 2013;84:1580-4.

6. Smilkstein G. Assessment of Family Function. In: Taylor RB, Rosen MG, Jacott WE, Donatelle EP, Buckingham JL, editors. Fundamentals of Family Medicine. New York, NY: Springer New York; 1983. p. 7484.

7. Steiner M, Streiner DL, Pham B. Validation of a Revised Visual Analog Scale for
Premenstrual Mood Symptoms: Results from Prospective and Retrospective Trials. 2005;50(6):327-32.

8. Vichnin M, Freeman EW, Lin H, Hillman J, Bui S. Premenstrual syndrome (PMS) in adolescents: severity and impairment. Journal of pediatric and adolescent gynecology. 2006;19(6):397-402.

9. Thu M, Diaz EO-Gja, Sawhsarkapa ja, editors. Premenstrual syndrome among female university students in Thailand2006.

10. Jahrami H, Algahtani HM, Haji EA, Al Jeeb A, Saif Z, Al Salman A. Prevalence and Impacts of Premenstrual Syndrome among Bahraini Women : A Cross - Sectional Study Using the Arab Premenstrual Syndrome Scale ( APMSS ). AJP. 2016;27(1):67-75.

11. Ahmed A, Hafez A, Mahmoud S, A E. Assessing the Premenstrual Syndrome and Coping Behavior Among Female Nursing Students. Al-Azhar Assiut Med J. 2015;13(4):179-84.

12. Elmalky ME, Ebrahem. SM. Effectiveness of Psycho- Educational Nursing Intervention on Adolescents' Premenstrual Syndrome and Self-Efficacy. Swift Journal of Nursing and Midwifery. 2015;1(1):001-11.

13. Delara M, Borzuei H, Montazeri A. Premenstrual disorders: prevalence and associated factors in a sample of Iranian adolescents. Iran Red Crescent Med J. 2013;15(8):695-700.

14. Bertone-Johnson ER, Hankinson SE, Willett WC, Johnson SR, Manson JE. Adiposity and 
the development of premenstrual syndrome. $\mathrm{J}$

Womens Health (Larchmt).

2010;19(11):1955-62.

15. Cheng SH, Shih CC, Yang YK, Chen KT, Chang YH, Yang YC. Factors associated with premenstrual syndrome - a survey of new female university students. The Kaohsiung journal of medical sciences. 2013;29(2):1005.

16. Farrokh-Eslamlou H, Oshnouei S, Heshmatian B, Akbari E. Premenstrual syndrome and quality of life in Iranian medical students. Sexual \& Reproductive Healthcare. 2015;6(1):23-7.

17. Raval CM, Panchal BN, Tiwari DS, Vala AU, Bhatt RB. Prevalence of premenstrual syndrome and premenstrual dysphoric disorder among college students of Bhavnagar, Gujarat. Indian J Psychiatry. 2016;58(2):164-70.

18. Seedhom AE, Mohammed ES, Mahfouz EM. Life Style Factors Associated with Premenstrual Syndrome among El-Minia University Students, Egypt. ISRN Public Health. 2013;2013:617123.

19. Bakr I, Ez-Elarab HSJTEJoCM. Prevalence of premenstrual syndrome and the effect of its severity on the quality of life among medical students. 2010;28(2):19-30.

20. Salem IMW, Alsamti MY, Murad MA. Predictors of Premenstrual Syndrome among Female Students at Governmental Secondary Schools in Jeddah, Saudi Arabia: A Crosssectional Study. The Egyptian Journal of Hospital Medicine. 2020;78(2):337-47.

21. Rasheed P, Al-Sowielem LS. Prevalence and predictors of premenstrual syndrome among college-aged women in Saudi Arabia. Annals of Saudi medicine. 2003;23(6):381-7.

22. Purdue-Smithe AC, Manson JE, Hankinson SE, Bertone-Johnson ER. A prospective study of caffeine and coffee intake and premenstrual syndrome. Am J Clin Nutr. 2016;104(2):499507.

23. Nicolau ZFM, Bezerra AG, Polesel DN, Andersen ML, Bittencourt L, Tufik S, et al. Premenstrual syndrome and sleep disturbances: Results from the Sao Paulo Epidemiologic Sleep Study. Psychiatry research. 2018;264:427-31. 
Table (1): Frequency Distribution of The Studied Population According to Their SocioDemographic and Study Characteristics $(\mathrm{N}=190)$

\begin{tabular}{|c|c|c|c|}
\hline & & $\mathbf{N}=190$ & $\%$ \\
\hline \multirow[t]{2}{*}{-Age (Years) } & Mean \pm SD & \multicolumn{2}{|c|}{$19.95(1.38)$} \\
\hline & Range & \multicolumn{2}{|c|}{$17-26$} \\
\hline \multirow[t]{2}{*}{-Faculty } & Practical & 75 & $39.5 \%$ \\
\hline & Theoretical & 115 & $60.5 \%$ \\
\hline \multirow[t]{3}{*}{-Study Year } & First & 73 & $38.4 \%$ \\
\hline & Middle Years & 93 & $48.9 \%$ \\
\hline & Final Year & 24 & $12.6 \%$ \\
\hline \multirow[t]{2}{*}{-Brother(s) } & None & 28 & $14.7 \%$ \\
\hline & One or more & 162 & $85.3 \%$ \\
\hline \multirow[t]{2}{*}{-Sister(s) } & None & 39 & $20.5 \%$ \\
\hline & One or more & 151 & $79.5 \%$ \\
\hline \multirow[t]{3}{*}{-Father's Education } & No Education & 5 & $2.6 \%$ \\
\hline & 1ry/2ry & 86 & $45.3 \%$ \\
\hline & University & 99 & $52.1 \%$ \\
\hline \multirow[t]{3}{*}{-Mother's Education } & No Education & 12 & $6.3 \%$ \\
\hline & 1ry/2ry & 98 & $51.6 \%$ \\
\hline & University & 80 & $42.1 \%$ \\
\hline \multirow[t]{3}{*}{-Marital Status } & Single & 167 & $87.9 \%$ \\
\hline & Engaged & 20 & $10.5 \%$ \\
\hline & Married & 3 & $1.6 \%$ \\
\hline
\end{tabular}


Table (2): Association between Premenstrual Tension Syndrome and Other Factors

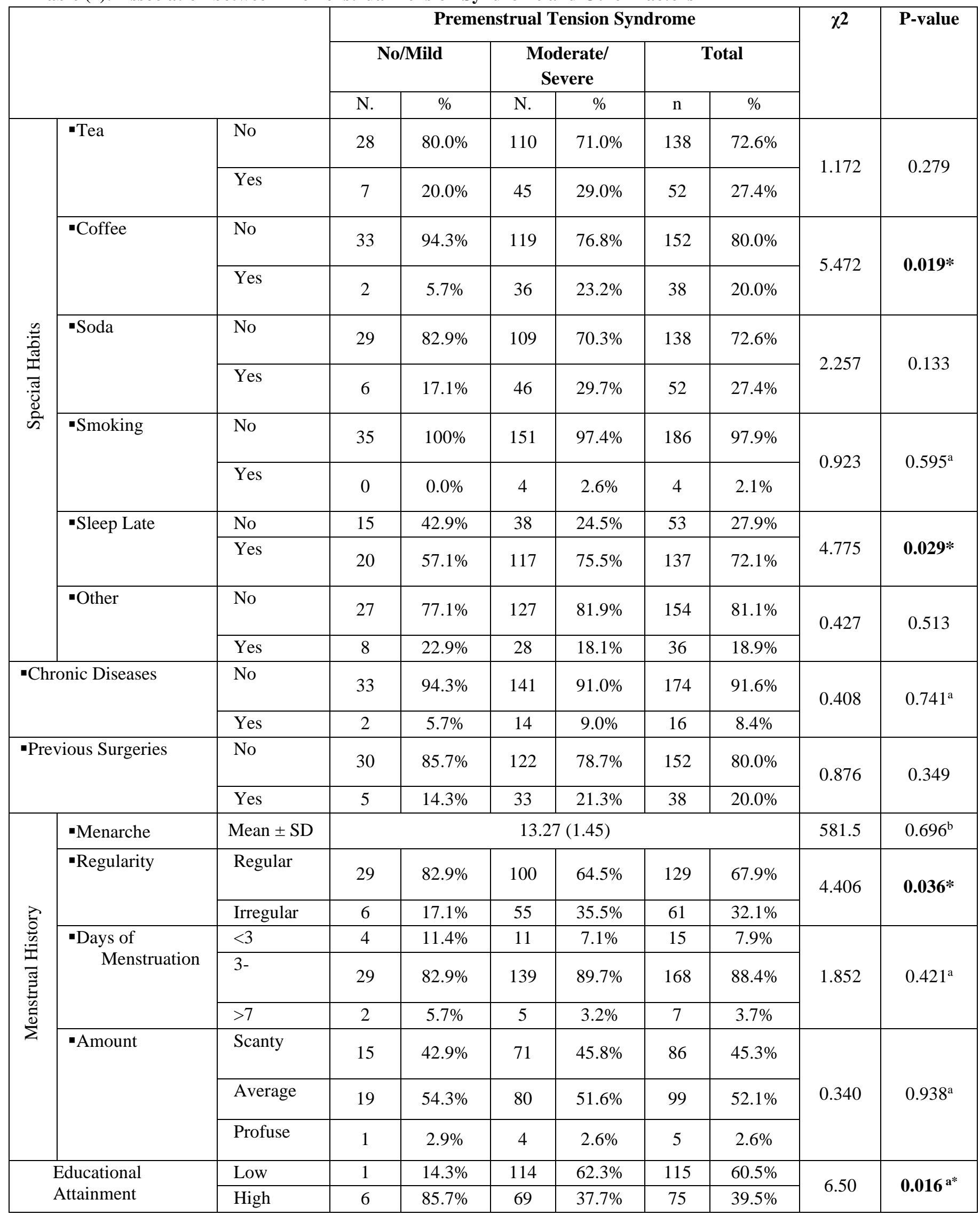

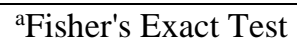

${ }^{b}$ Mann-Whitney U Test

* Statistically significant at $\mathrm{P}<0.05$.

Egyptian Family Medicine Journal (EFMJ)

Vol .5(1), May 2021

http://efmj.journals.ekb.eg/

(c) This article is an open access article distributed under the terms and conditions of the Creative Commons Attribution (CC BY) license (http://creativecommons.org/licenses/by/4.0/ 
Table (3): Association between Family Function and Medical Conditions, Menstrual History and PMTS

\begin{tabular}{|c|c|c|c|c|c|c|c|c|c|}
\hline & \multicolumn{4}{|c|}{ Family APGAR } & \multirow{2}{*}{\multicolumn{2}{|c|}{ Total }} & \multirow[t]{3}{*}{$\chi^{2}$} & \multirow{3}{*}{$\begin{array}{c}\text { P- } \\
\text { value }\end{array}$} \\
\hline & & \multicolumn{2}{|c|}{$\begin{array}{c}\text { Highly } \\
\text { functional }\end{array}$} & \multicolumn{2}{|c|}{$\begin{array}{l}\text { Moderate/Severe } \\
\text { dysfunction }\end{array}$} & & & & \\
\hline & & N. & $\%$ & N. & $\%$ & N. & $\%$ & & \\
\hline \multirow[t]{4}{*}{ BMI } & - Underweight & 6 & $8.1 \%$ & 9 & $7.8 \%$ & 15 & $7.9 \%$ & \multirow{4}{*}{0.023} & \multirow{4}{*}{0.99} \\
\hline & -Normal & 37 & $50.0 \%$ & 59 & $50.9 \%$ & 96 & $50.5 \%$ & & \\
\hline & -Overweight & 23 & $31.1 \%$ & 36 & $31.0 \%$ & 59 & $31.1 \%$ & & \\
\hline & - Obese & 8 & $10.8 \%$ & 12 & $10.3 \%$ & 20 & $10.5 \%$ & & \\
\hline \multirow{2}{*}{$\begin{array}{l}\text { Chronic } \\
\text { Disease(s) }\end{array}$} & - No & 66 & $89.2 \%$ & 108 & $93.1 \%$ & 174 & $91.6 \%$ & \multirow{2}{*}{0.898} & \multirow{2}{*}{0.34} \\
\hline & - Yes & 8 & $10.8 \%$ & 8 & $6.9 \%$ & 16 & $8.4 \%$ & & \\
\hline \multirow{2}{*}{$\begin{array}{l}\text { Previous } \\
\text { Surgery }\end{array}$} & - No & 57 & $77.0 \%$ & 95 & $81.9 \%$ & 152 & $80.0 \%$ & \multirow{2}{*}{0.670} & \multirow{2}{*}{0.41} \\
\hline & - Yes & 17 & $23.0 \%$ & 21 & $18.1 \%$ & 38 & $20.0 \%$ & & \\
\hline Menarche & - Mean \pm SD & \multicolumn{6}{|c|}{$13.27(1.45)$} & 4026 & $0.464^{\mathrm{b}}$ \\
\hline \multirow{2}{*}{$\begin{array}{l}\text { Regularity of } \\
\text { Menstruation }\end{array}$} & - Regular & 57 & $77.0 \%$ & 72 & $62.1 \%$ & 129 & $67.9 \%$ & \multirow{2}{*}{4.637} & \multirow{2}{*}{$\mathbf{0 . 0 3} *$} \\
\hline & - Irregular & 17 & $23.0 \%$ & 44 & $37.9 \%$ & 61 & $32.1 \%$ & & \\
\hline \multirow{3}{*}{$\begin{array}{l}\text { Days of } \\
\text { Menstruation }\end{array}$} & $-<3$ & 6 & $8.1 \%$ & 9 & $7.8 \%$ & 15 & $7.9 \%$ & \multirow{3}{*}{1.689} & \multirow{3}{*}{$0.42^{\mathrm{a}}$} \\
\hline & $-3-7$ & 67 & $90.5 \%$ & 101 & $87.1 \%$ & 168 & $88.4 \%$ & & \\
\hline & ->7 & 1 & $1.4 \%$ & 6 & $5.2 \%$ & 7 & $3.7 \%$ & & \\
\hline \multirow[t]{3}{*}{ Amount } & -Scanty & 31 & $41.9 \%$ & 55 & $47.4 \%$ & 86 & $45.3 \%$ & \multirow{3}{*}{1.414} & \multirow{3}{*}{$0.45^{\mathrm{a}}$} \\
\hline & - Average & 42 & $56.8 \%$ & 57 & $49.1 \%$ & 99 & $52.1 \%$ & & \\
\hline & -Profuse & 1 & $1.4 \%$ & 4 & $3.4 \%$ & 5 & $2.6 \%$ & & \\
\hline \multirow[t]{4}{*}{ PMTS } & - No & 6 & $8.1 \%$ & 1 & $0.9 \%$ & 7 & $3.7 \%$ & \multirow{4}{*}{17.38} & \multirow{4}{*}{$0.00 * a$} \\
\hline & -Mild & 18 & $24.3 \%$ & 10 & $8.6 \%$ & 28 & $14.7 \%$ & & \\
\hline & - Moderate & 29 & $39.2 \%$ & 51 & $44.0 \%$ & 80 & $42.1 \%$ & & \\
\hline & - Severe & 21 & $28.4 \%$ & 54 & $46.6 \%$ & 75 & $39.5 \%$ & & \\
\hline
\end{tabular}

${ }^{\text {a}}$ Fisher's Exact Test

${ }^{\mathrm{b}}$ Mann-Whitney U Test

* Statistically significant at $\mathrm{P}<0.05$. 
Table (4): Logistic Regression Analysis for Predictors of Family Dysfunction

\begin{tabular}{|c|c|c|c|c|c|c|}
\hline & \multirow{2}{*}{ Coefficient } & \multirow{2}{*}{ Wald } & \multirow{2}{*}{$p$-value } & \multirow{2}{*}{$\begin{array}{l}\text { Adjust } \\
\text { ed } \\
\text { Odds } \\
\text { Ratio }\end{array}$} & \multicolumn{2}{|c|}{$\begin{array}{l}\text { 95\% Confidence } \\
\text { Interval }\end{array}$} \\
\hline & & & & & Lower & Upper \\
\hline - Age & 0.022 & 0.018 & 0.893 & 1.023 & 0.738 & 1.418 \\
\hline $\begin{array}{l}\text { - Study Year (Middle } \\
\text { Years) }\end{array}$ & -.0213 & 0.287 & 0.592 & 0.808 & 0.371 & 1.762 \\
\hline $\begin{array}{ll}\text { - Study Year (Final } \\
\text { Year) }\end{array}$ & -0.341 & 0.233 & 0.629 & 0.711 & 0.178 & 2.844 \\
\hline - $\quad$ BMI(Normal) & 0.286 & 0.231 & 0.631 & 1.331 & 0.414 & 4.281 \\
\hline - BMI(Overweight) & 0.391 & 0.389 & 0.533 & 1.478 & 0.433 & 5.051 \\
\hline - BMI(Obese) & 0.024 & 0.001 & 0.973 & 1.024 & 0.247 & 4.241 \\
\hline $\begin{array}{l}\text { Regularity of } \\
\text { Menstruation }\end{array}$ & 0.537 & 2.240 & 0.134 & 1.711 & 0.847 & 3.455 \\
\hline - $\quad$ PMTS(Mild) & 1.234 & 1.133 & 0.287 & 3.434 & 0.354 & 33.302 \\
\hline - PMTS(Moderate) & 2.368 & 4.440 & $0.035 *$ & 10.676 & 1.180 & 96.589 \\
\hline - PMTS(Severe) & 2.730 & 5.802 & $0.016 *$ & 15.327 & 1.663 & 141.285 \\
\hline - Constant & -2.526 & 0.582 & 0.446 & 0.080 & & \\
\hline
\end{tabular}

Reference categories: Study Year (First), BMI (Underweight), Regularity of Menstruation (Regular), PMTS (No).

Omnibus Tests for Model fit (p-value $=0.017)$

Overall model prediction: $66.8 \%$

* Statistically significant at $\mathrm{p}<0.05$ 


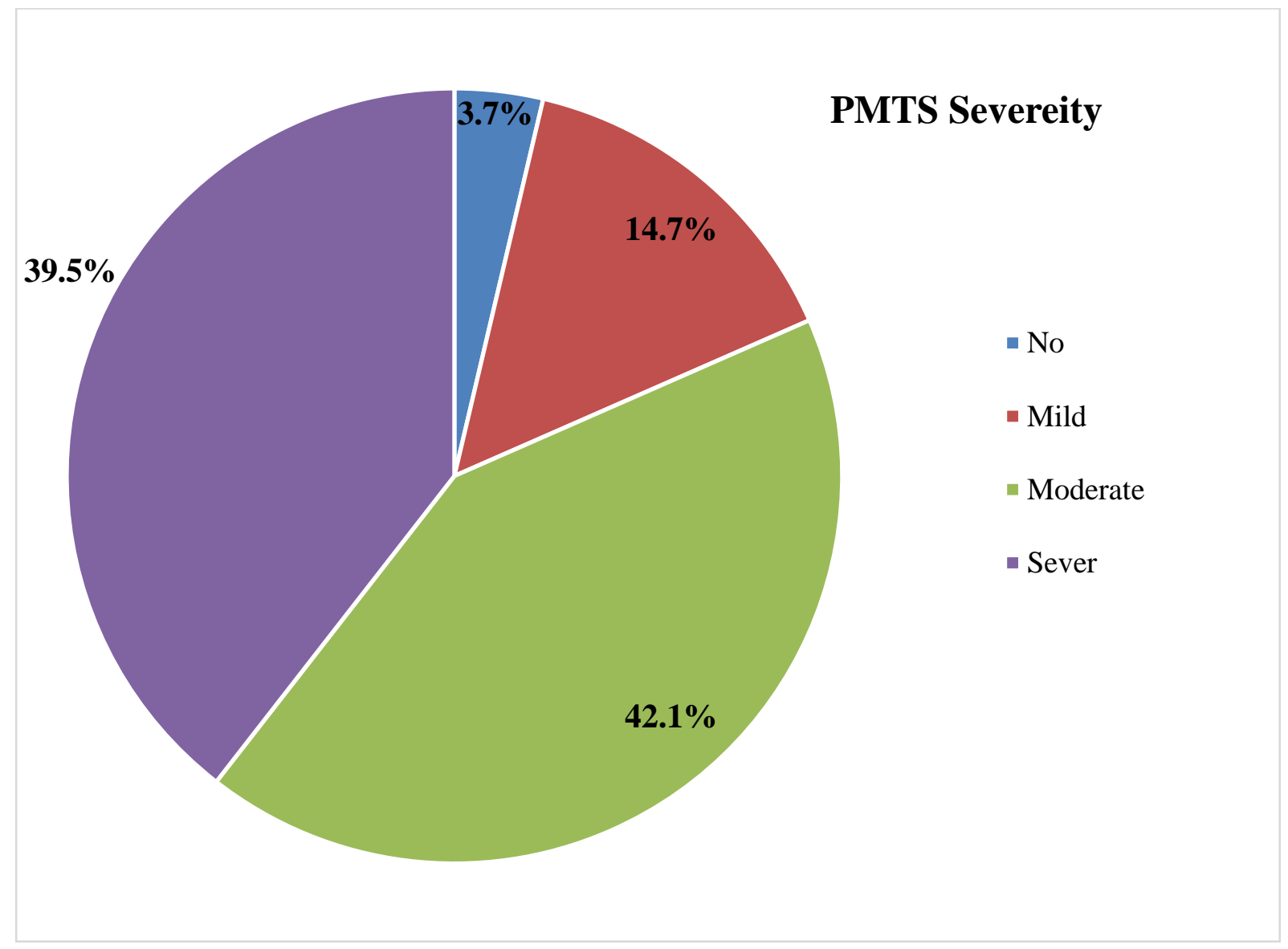

Figure (1): Frequency of Premenstrual Tension Syndrome Severity among Participants

\section{متلازمة ما قبل الحيض و أثرها العربي وظيفة الأسرة}

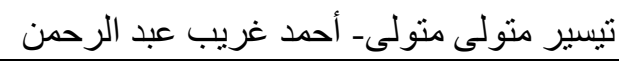

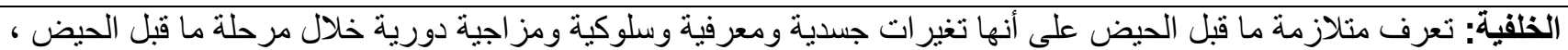

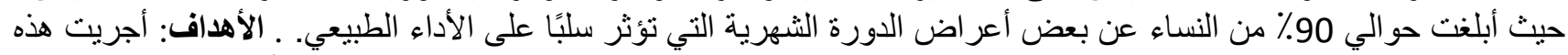

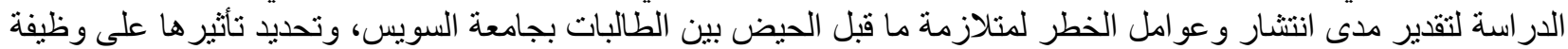

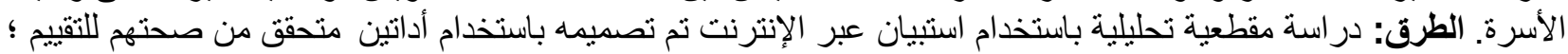

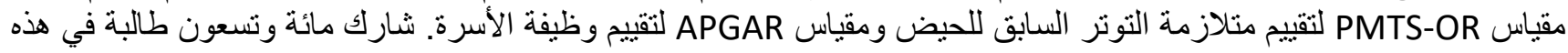

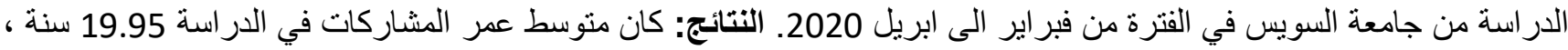

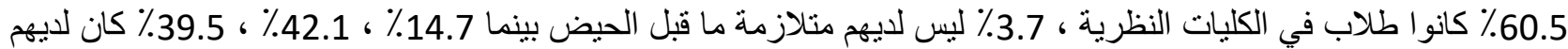

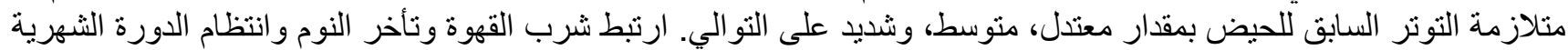

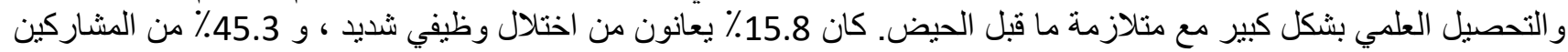

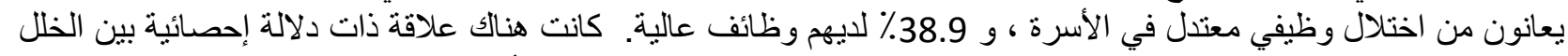

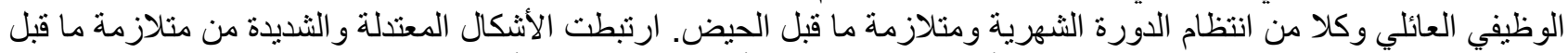

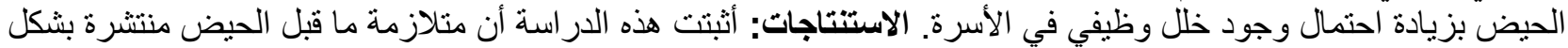

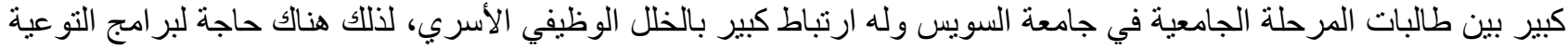
الصحية للفتيات و عائلاتهن لتحسين المعرفة فيما يتعلق باضطر ابات الدينة الدورة الثهرية. 